\title{
Antibacterial Screening of Crude Fractions of Calotropis Procera (Linn) and Gc-Ms Profile of Fractions Obtained from the Extracts of Calotropis Procera
}

\author{
Asoso Oluwakemi Sola ${ }^{1 *}$, Oladunmoye $\mathrm{MK}^{2}$ and Ogundare ${ }^{2}$ \\ ${ }^{1}$ Department of Microbiology, Nigeria \\ ${ }^{2}$ Department of Biological Sciences, Nigeria \\ *Corresponding author: Asoso Oluwakemi Sola, Department of Microbiology, Nigeria
}

\begin{abstract}
ARTICLE INFO
Received: 㟒 May 21, 2019

Published: 蔧 May 22, 2019

Citation: Asoso Oluwakemi S, Oladunmoye MK, Ogundare. Antibacterial Screening of Crude Fractions of Calotropis Procera (Linn) and Gc-Ms Profile of Fractions Obtained from the Extracts of Calotropis Procera. Biomed J Sci \& Tech Res 18(2)-2019. BJSTR. MS.ID.003124.
\end{abstract}

Keywords: Calotropis Procera; Gc-Ms, Analysis; Crude Fractions; Leaves; Stem

\begin{abstract}
Traditional medicine also known as Indigenous or folk medicine comprises of knowledge systems that developed over generations within various societies before the era of modern medicine. The World Health Organization (WHO) defines traditional medicine as the sum of total of the knowledge, skills, and practices based on the theories, beliefs and experiences indigenous to different cultures, whether explicable or not, used in the maintenance of health as well as in the prevention, diagnosis, improvement or treatment of physical and mental illness. The column chromatography was used to collect the crude fractions; solvents like petroleum ether, chloroform and methanol were used. The antibacterial activities of the crude fractions of Calotropis procera (leaf and stem) were evaluated in this study using some selected microorganisms like Escherichia coli, Shigella dysenteriae ATCC 24162, Salmonella typhi and Klebsiella pneumoniae ATCC 34089 , whereby the plant was extracted using (acetone, methanol and aqueous). The paper disc method was used after which the zone of inhibition around the discs was estimated. The results showed that in the leaf of the plant; E. coli with Aqueous-methanol fraction and K. pneumoniae ATCC 34089 with acetone-petroleum ether fraction had the highest yield of $30 \mathrm{~mm}$ respectively while in stem; K. pneumoniae ATCC 34089 with methanol-methanol fraction had the highest yield of $25 \mathrm{~mm}$. The structural elucidation of the bioactive compounds in the extracts were evaluated using Gc-Ms (Gas Chromatography-Mass Spectophotometry) which reveals the chemical compounds like phenol, methyl palmitate, Phthalic acid, 9-octadecenoic acid and other compounds known for valuable antimicrobial, biological activities and antioxidant properties. The leaves and the stem are having good chemical compounds that can be responsible for the antimicrobial and antioxidant properties.
\end{abstract}

\section{Introduction}

The use of herbal medicine as alternative therapy has prevalent throughout the world due to the growing resistance of pathogens to conventional antibiotics De Smet [1]. The need for more potent, safe and affordable drugs has led to intensified research into herbal drugs, the result of which is the introduction of new herbal preparation for therapeutic uses Griggs et al. [2]. Medicinal plants are frequently used as remedies for many infectious diseases Ahmed et al. [3]. The treatment and control of diseases by the use of the available medicinal plants in a locality have been helpful and of a priority to majority of urban and rural dwellers in healing various diseases because of the reliability and stability in plant products for healing Akharaiyi et al. [4] Calotropis procera (Apple of Sodom) is a shrub or small tree, which has become a serious weed in pastures and overgrazed rangelands. It is a native to West Africa as far as south as Angola, North and East African, Madagascar, the Arabian Peninsula, Southern Asia, India and China to Malaysia. Calotropis was formerly placed in the family of Asclepiadaceous (the milkweed family), which is now considered a subfamily of the Apocynaceae Stevens [5]. 


\section{Materials and Method}

\section{Collection of Plant Samples}

Apparently healthy plant namely C. procera were collected from Ado-Ekiti, Ekiti State Nigeria.

\section{Preparations of Plant Extracts}

The plants parts leaves and stem were air-dried for 5 weeks at room temperature $\left(25+2^{\circ} \mathrm{C}\right)$ and then ground to powder with a mechanical grinder (Thomas Wiley machine, model 5 USA). Powders (200gs) of each plant were extracted with 1litre of sterile aqueous water, ethanol, methanol and acetone separately at room temperature $\left(25+2^{\circ} \mathrm{C}\right)$. They were labeled as crude extracts.

\section{Antibacterial Screening of the Crude Fractions}

The evaluation of antimicrobial activity was performed for all fractions by the paper disc agar diffusion method following the standard rules of antimicrobial sensitivity tests by the Clinical and Laboratory Standards Institute (CLSI, 2015). The antibacterial effect of the fractions was carried out whereby the discs were previously impregnated with the plant crude fractions and placed on the sterile prepared medium. The plates were incubated at $37^{\circ} \mathrm{C}$ for 24-48 hours. The sensitivity of the test organisms to each of the extracts was indicated by clearing around each disc. The diameter as an index of the degree of sensitivity was measured with a transparent plastic ruler.

\section{Column Chromatography and Fraction Extracts}

Glass wool was placed at the outlet of a column after which, one gram of plant extract powder was weighed into it and subjected to column chromatography ( $30 \mathrm{x} 8 \mathrm{~cm}$ column) using $60 \mathrm{~g}$ of silica gel 60 F254 (Merck, $0.020 \mathrm{~mm}$ thickness). The column was successively eluted first with petroleum ether $(150 \mathrm{ml})$ and then with chloroform (80ml): methanol (2ml) (40: 1) and finally with $100 \%$ methanol $(150 \mathrm{ml})$. Each $100 \mathrm{ml}$ eluent was collected into a round bottom flask $(250 \mathrm{ml})$ capacity and distilled to obtain fractions. The fractions collected were numbered. Gc-Ms analysis was carried out in GCMS-QP2010 PLUS shamadzu.

\section{Results}

\section{Antibacterial Screening of Crude Fractions}

The Antibacterial screening of the crude fractions of Calotropis procera leaf was examined; some chemicals were used in the fractionalization of the crude sample, which are methanol, chloroform and petroleum ether. Methanol, Aqueous and Acetone leaf fractions showed the highest zone of inhibition of 30, 20 and $20 \mathrm{~mm}$ respectively. The use of petroleum Ether do not show any significant antibacterial effects against the isolates while aqueous crude fractions shows an effective antibacterial activity against $S$. aureus at zone of inhibition of $15 \mathrm{~mm}$ (Table 1). This table presents the antibacterial screening of the stem crude fractions to indicate the effectiveness of various bioactive or metabolite fractions found in the crude stem extracts of the plant (C. procera). During this research, also methanol was found to show a significant antibacterial effect on K. pneumoniae at zone of inhibition of $25 \mathrm{~mm}$. Both methanol and aqueous crude fractions have shown good antibacterial activities (Table 2). These plates indicate the Gc-ms analysis with peaks of secondary metabolites of the crude fractions. These shows different peaks which implies different chemical compounds that are been found in the fractions (Figures 1-6). The chemical compounds of the crude fractions were determined and listed out with their retention time and the concentration of the chemical compounds in percentage. The chemical compounds found are phenol, methyl palmitate, 9-octadecenoic acid, Phthalic acid, Dimethyl Sulfoxide, Phytol etc. (Tables 3-8).

Table 1: Antibacterial screening of crude fractions of Calotropis procera leaf ( $\mathrm{mm}$ ).

\begin{tabular}{|c|c|c|c|c|c|c|c|c|c|c|c|c|}
\hline ORGS & ACM & ACC & ACP & MM & MC & MP & $\mathrm{AQM}$ & AQP & $\mathrm{AQC}$ & EC & EP & EM \\
\hline E.coli & 0 & 0 & 0 & 4 & 20 & 2 & 30 & 0 & 20 & 0 & 0 & 0 \\
\hline S. Aureus & 0 & 0 & 0 & 10 & 5 & 0 & 0 & 0 & 15 & 0 & 0 & 0 \\
\hline E.coli ATCC 35218 & 0 & 0 & 0 & 0 & 20 & 0 & 0 & 0 & 0 & 0 & 0 & 0 \\
\hline S. Typhi & 20 & 15 & 20 & 18 & 5 & 0 & 0 & 0 & 0 & 10 & 5 & 7 \\
\hline S. Dysenteriae & 20 & 0 & 0 & 14 & 0 & 0 & 0 & 0 & 0 & 4 & 14 & 0 \\
\hline S. Dysenteriae ATCC 24162 & 2 & 0 & 0 & 22 & 14 & 2 & 0 & 0 & 0 & 0 & 0 & 0 \\
\hline K. Pneumonia ATCC 34089 & 20 & 0 & 30 & 0 & 0 & 0 & 0 & 0 & 0 & 0 & 0 & 0 \\
\hline K. Pneumoniae & 24 & 2 & 0 & 0 & 0 & 0 & 0 & 0 & 0 & 0 & 0 & 0 \\
\hline
\end{tabular}

Note: ACM- Acetone methanol, ACC-Acetone Chloroform, ACP-Acetone Pet. Ether, MM-methanol methanol, MC-Methanol Chloroform, MP-Methanol pet. Ether, AQC-Aqueous Chloroform, AQP Aqueous Pet.ether, AQM- Aqueous Methanol, EM-Ethanol Methanol, EC- Ethanol Chloroform, EP- Ethanol Pet. Ether.

Table 2: Antibacterial screening of crude fractions of Calotropis procera (Linn) stem (mm).

\begin{tabular}{|c|c|c|c|c|c|c|c|c|c|c|c|c|}
\hline ORGS & ACM & ACC & ACP & MM & MC & MP & $\mathrm{AQC}$ & $\mathrm{AQP}$ & $\mathrm{AQM}$ & EM & EC & EP \\
\hline E. coli & 0 & 0 & 0 & 0 & 0 & 0 & 0 & 0 & 5 & 0 & 0 & 0 \\
\hline S. Dysenteriae ATCC 24162 & 0 & 0 & 0 & 0 & 0 & 0 & 10 & 3 & 3 & 6 & 0 & 0 \\
\hline K. Pneumonia ATCC 34089 & 0 & 0 & 0 & 25 & 0 & 9 & 0 & 0 & 0 & 0 & 0 & 0 \\
\hline
\end{tabular}




\begin{tabular}{|c|c|c|c|c|c|c|c|c|c|c|c|c|}
\hline S. Typhi & 0 & 5 & 10 & 2 & 0 & 7 & 0 & 0 & 21 & 6 & 0 & 0 \\
\hline E. coli & 0 & 0 & 0 & 0 & 0 & 0 & 0 & 0 & 5 & 0 & 0 & 0 \\
\hline S. Dysenteriae ATCC 24162 & 0 & 0 & 0 & 0 & 0 & 0 & 10 & 3 & 3 & 6 & 0 & 0 \\
\hline K. Pneumonia ATCC 34089 & 0 & 0 & 0 & 25 & 0 & 9 & 0 & 0 & 0 & 0 & 0 & 0 \\
\hline S. Typhi & 0 & 5 & 10 & 2 & 0 & 7 & 0 & 0 & 21 & 6 & 0 & 0 \\
\hline
\end{tabular}

Note: ACM- Acetone methanol, ACC- Acetone Chloroform, ACP-Acetone Pet. Ether, MM-methanol methanol, MC-Methanol

Chloroform, MP-Methanol pet. Ether, AQC-Aqueous Chloroform, AQP-Aqueous Pet.ether, AQM- Aqueous Methanol, EM-Ethanol Methanol, EC- Ethanol Chloroform, EP- Ethanol Pet. Ether.

Table 3: chemical compounds of the fraction of mms (Methanol Methanol Stem).

\begin{tabular}{|c|c|c|c|}
\hline S/N & Chemical Compounds & Retention Time (Mins) & Concentration (\%) \\
\hline 1 & Phenol & 14.725 & 1.761 \\
\hline 2 & Methyl palmitate & 38.401 & 7.053 \\
\hline 3 & 9-octadecadienoic acid & 39.627 & 2.814 \\
\hline 4 & Octadecadienoic acid & 39.666 & 4.602 \\
\hline 5 & Methyl9,12-hepatadecadienoate & 40.184 & 34.65 \\
\hline 6 & 9-octadecenoic acid & 40.255 & 8.98 \\
\hline 7 & Tetradecanoic acid & 40.703 & 31.16 \\
\hline 9 & Phthalic acid & 41.080 & 4.21 \\
\hline
\end{tabular}

Table 4: Chemical compounds of the fraction of mas (methanol aqueous stem).

\begin{tabular}{|c|c|c|c|}
\hline S/N & Chemical Compounds & Retention Time (Mins) & Concentration (\%) \\
\hline 1 & Hydrazine & 7.797 & 0.92 \\
\hline 2 & Thietane & 7.876 & 0.86 \\
\hline 3 & Dimethyl Sulfoxide & 9.282 & 13.23 \\
\hline 4 & 2 (5H)-Furanone & 11.905 & 13.53 \\
\hline 5 & Triacetin & 23.798 & 1.22 \\
\hline 6 & 4-methyl-5-methoxy-1,2,4-triazole-3-thione & 1.33 \\
\hline 7 & Methyl palmitate & 24.018 & 4.40 \\
\hline 8 & 9-octadecenoic acid & 38.386 & 0.69 \\
\hline 9 & Methyl palmitate & 39.650 & 2.08 \\
\hline 10 & Benzenemethanamine & 39.807 & 11.17 \\
\hline 11 & Phthalic acid & 41.512 & 18.97 \\
\hline 12 & 1H-Indole & 42.109 & 22.26 \\
\hline 13 & 2-methyl-7-phenylindole & 42.219 & 7.24 \\
\hline 14 & (2,3-Diphenylcyclopropyl) methylphenyl sulfoxide & 42.345 & 2.09 \\
\hline
\end{tabular}

Table 5: Chemical compounds of the fraction of Cal (Chloroform Aqueous Leaf).

\begin{tabular}{|c|c|c|c|}
\hline S/N & Chemical Compounds & Retention Time (Mins) & Concentration (\%) \\
\hline 1 & Dodecane & 15.802 & 1.67 \\
\hline 2 & Phenol & 29.061 & 2.79 \\
\hline 3 & Cyclohexadecane & 31.151 & 1.55 \\
\hline 4 & $9-$-octadecene & 36.744 & 1.68 \\
\hline 5 & Dodecane & 36.744 & 1.22 \\
\hline 6 & Phthalic acid & 37.435 & 4.64 \\
\hline 7 & Phthalic acid & 37.749 & 37.68 \\
\hline 8 & Methyl palmitate & 12.72 \\
\hline 9 & 9 -octadecenoic acid & 38.401 & 12.72 \\
\hline 11 & Methyl palmitate & 39.658 & 8.60 \\
\hline
\end{tabular}


Table 6: Chemical compounds of the fraction of pal (pet-ether acetone leaf).

\begin{tabular}{|c|c|c|c|}
\hline S/N & Chemical Compounds & Retention Time (Mins) & Concentration (\%) \\
\hline 1 & 2-Hexadecene & 37.380 & 1.29 \\
\hline 2 & 11-tetradecyn-1-ol acetate & 37.451 & 2.94 \\
\hline 3 & 2-pentadecanone & 37.521 & 10.40 \\
\hline 4 & Phthalic acid & 37.741 & 24.54 \\
\hline 5 & 3,7,11,15-tetramethyl-2-hexadecenol-ol & 37.953 & 2.70 \\
\hline 6 & Methyl palmitate & 38.393 & 7.66 \\
\hline 7 & Hexadecanoic acid & 38.951 & 0.97 \\
\hline 8 & 9,12-octadecadienoic acid(z,z)-methyl ester & 39.611 & 1.80 \\
\hline 9 & 7,10,13-hexadecatrienoic acid & 39.650 & 5.53 \\
\hline 10 & Phytol & 39.744 & 28.64 \\
\hline 11 & Methyl palmitate & 39.815 & 2.75 \\
\hline 12 & Cyclopentanone & 39.909 & 1.11 \\
\hline 13 & Bromacetic acid & 40.577 & 3.88 \\
\hline 14 & $\begin{array}{l}\qquad, 8,12,16 \\
\text { tetramethylheptadecan-4-olide }\end{array}$ & 40.993 & 3.88 \\
\hline 15 & Phthalic acid & 42.101 & 2.66 \\
\hline
\end{tabular}

Table 7: Chemical Compounds of the fraction of MML(Methanol Methanol Leaf).

\begin{tabular}{|c|c|c|c|}
\hline S/N & Chemical Compounds & Retention Time (Mins) & Concentration (\%) \\
\hline 1 & Dimethyl sulfoxide & 9.400 & 91.44 \\
\hline 2 & 3-acetoxy-3-hydroxypropionic acid & 16.878 & 5.05 \\
\hline 3 & Methyl palmitate & 38.401 & 3.51 \\
\hline
\end{tabular}

Table 8: Chemical compounds of the fraction of MAL (methanol Aqueous Leaf).

\begin{tabular}{|c|c|c|c|}
\hline S/N & Chemical Compounds & Retention Time (Mins) & Concentration (\%) \\
\hline 1 & Butane & 9.965 & 65.81 \\
\hline 2 & n- hexadecanoic acid & 39.116 & 26.20 \\
\hline 3 & 9-octadecenoic acid & 40.074 & 2.20 \\
\hline 4 & Octadecanoic acid & 40.208 & 5.79 \\
\hline
\end{tabular}

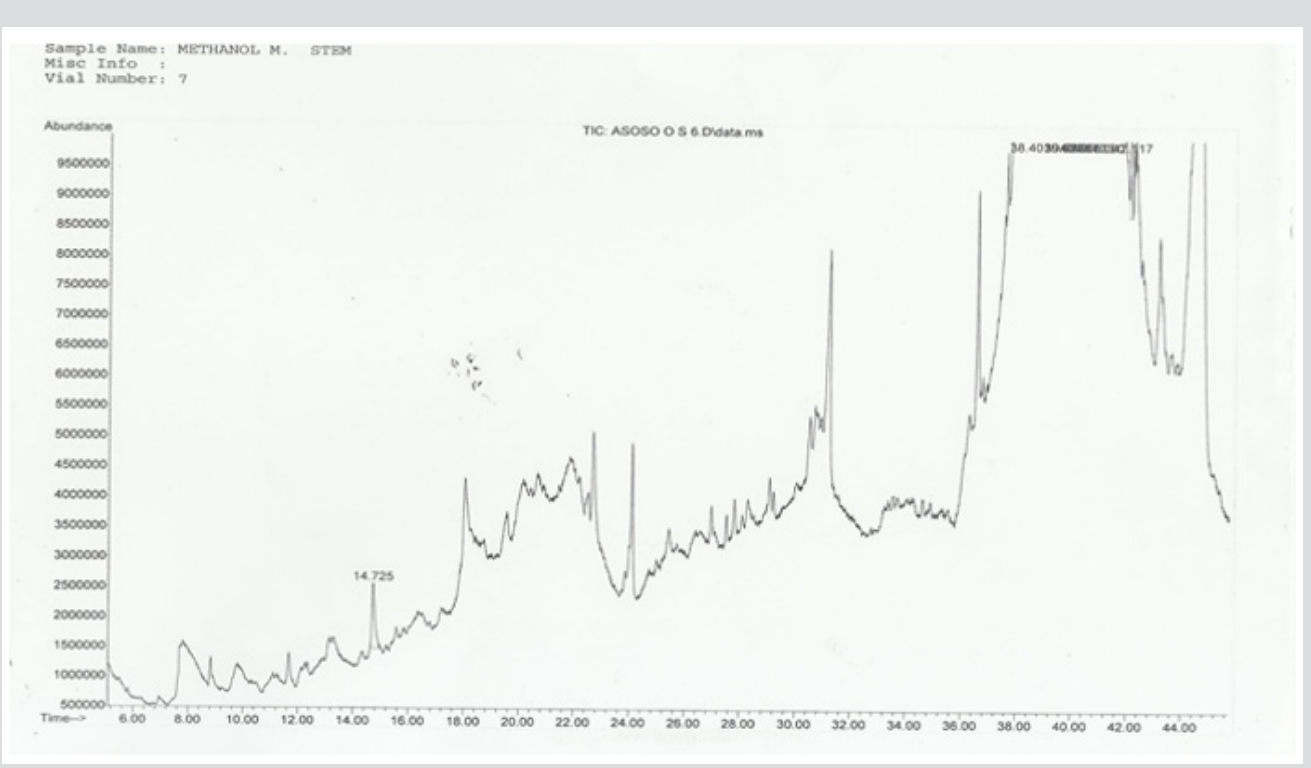

Figure 1: Gc-Ms Analysis with Peaks of Secondary Metabolites of MMS (Methanol Methanol Stem Fraction). 


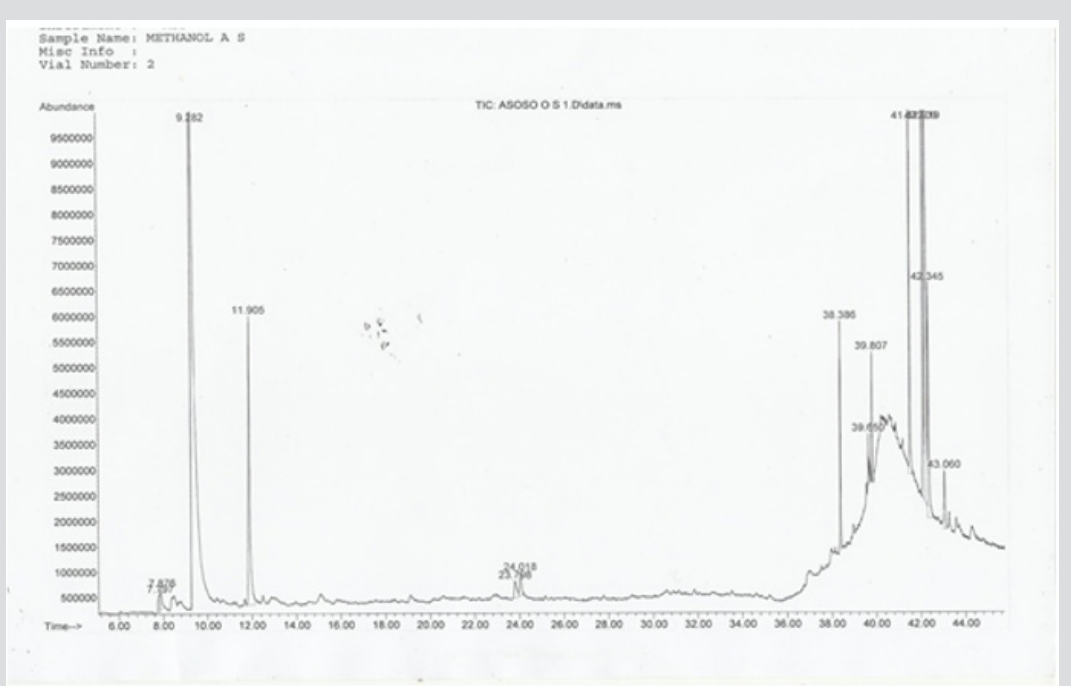

Figure 2: Gc-Ms Analysis with Peaks of Secondary Metabolites of MAS (Methanol Aqueous Stem Fraction).

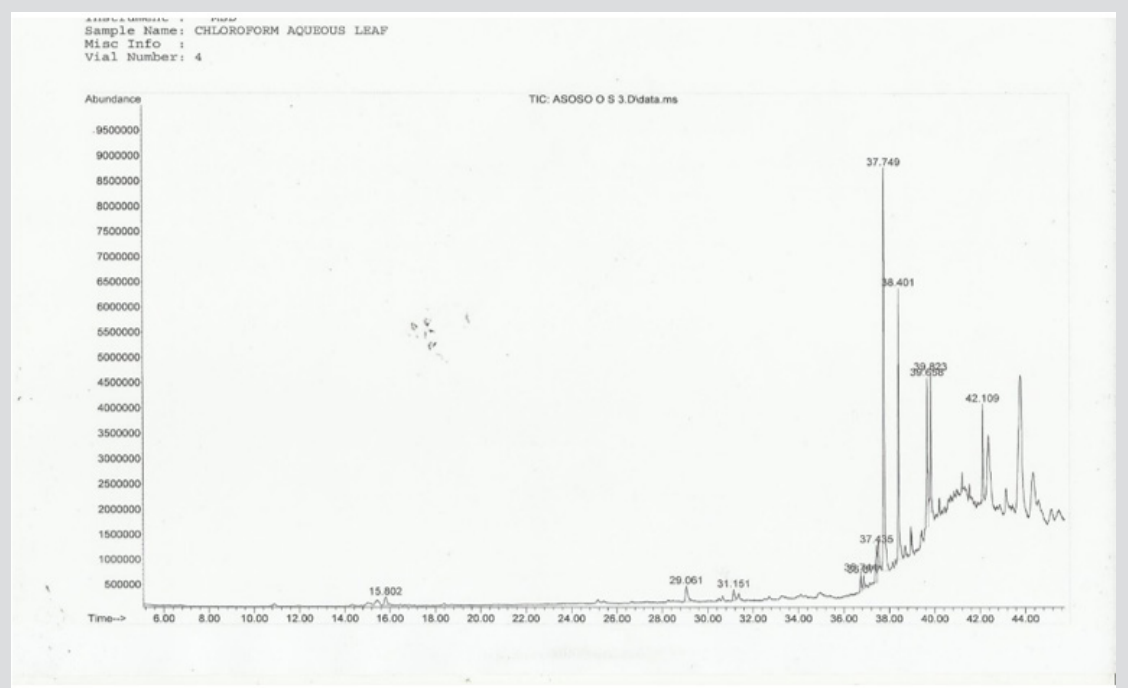

Figure 3: Gc-Ms Analysis with Peaks of Secondary Metabolites of CAL (Chloroform Aqueous Leaf Fraction).

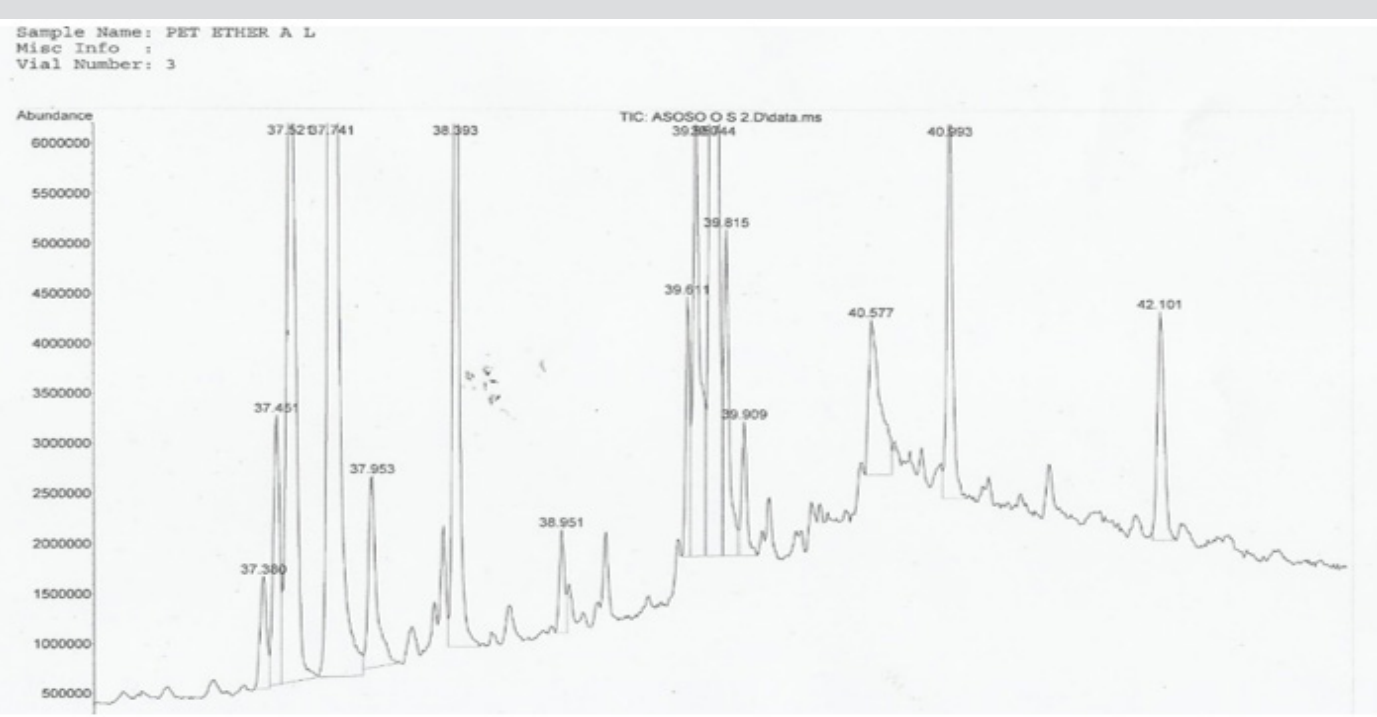

Figure 4: Gc-Ms Analysis with Peaks of Secondary Metabolites of PAL (Pet-Ether Acetone Leaf Fraction). 


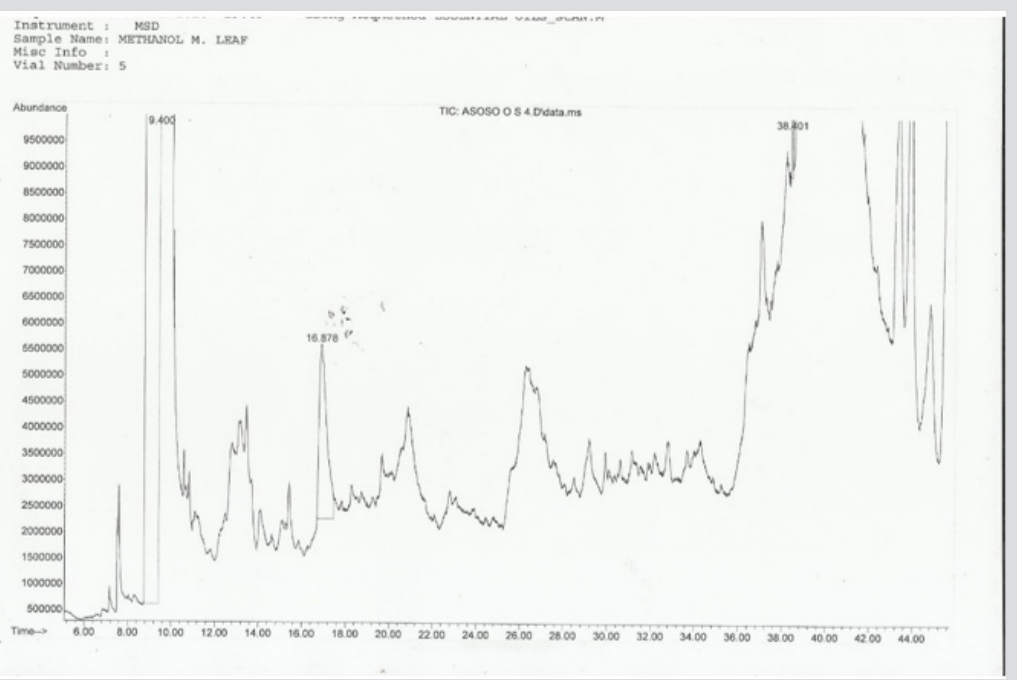

Figure 5: Gc-Ms Analysis with Peaks of Secondary Metabolites of MML (Methanol Methanol Leaf Fraction).

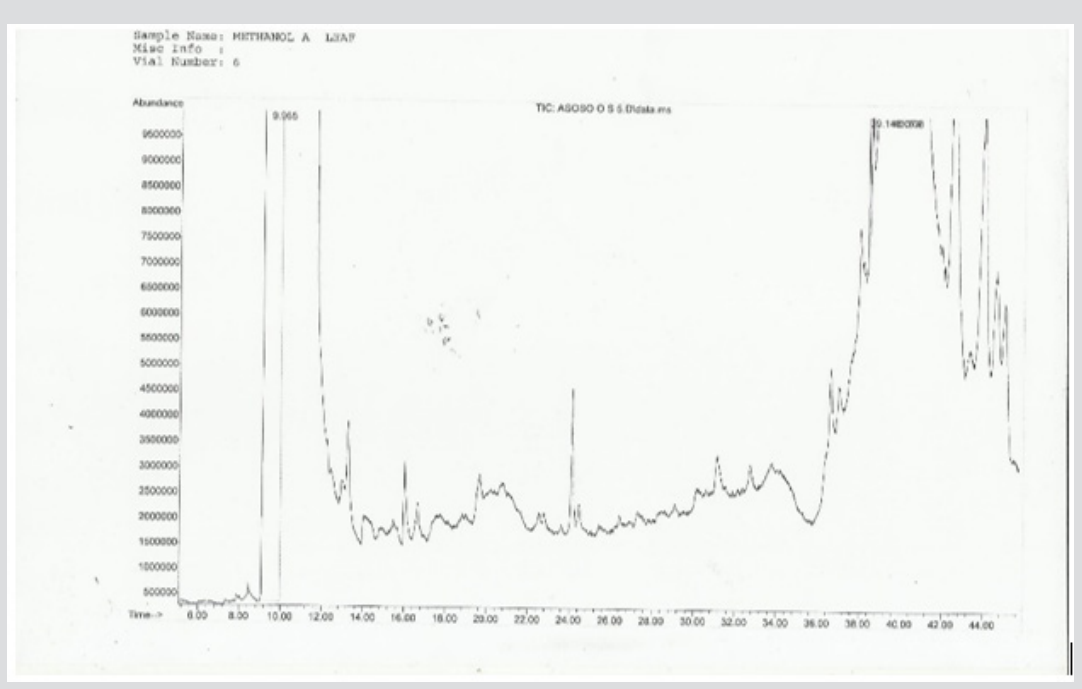

Figure 6: Gc-Ms Analysis with peaks of secondary metabolites of Mal (Methanol Aqueous Leaf Fraction).

\section{Discussion}

Antibacterial activities of the crude fractions showed that this plant can be used for curing many diseases such as pneumonia, dysentery etc. The results demonstrated that the crude extracts were more efficient than the fractions, this findings might suggest that Phytochemical constituents in combination may be having synergy in their efficacy, which is in agreement with many other report that have shown higher antibacterial potency of crude extracts as compared to the fraction Martins et al. [6]. The difference of various plant extracts in the antimicrobial activity is expected, as the activity is based not only on the different structures of microorganisms but also on their susceptibilities Zhang et al. [7]. This inhibitory action could be attributed to the phytochemical constituents, since these constituents are well established as antimicrobial agents Nenaah [8]. In the present study, in the agar diffusion assay the methanol and chloroform extracts showed the larger inhibition halo enabling to observe the extraction potential of the solvent employed. Differences in the activity between the fractions can be partly explained by quantitative and qualitative variations in the secondary metabolites present in the fractions which are in support with Ogundare et al. $[9,10]$ and could be due to the use of different parts of the plants and leading to the extraction of different compounds and with antimicrobial activity. GC-MS technique was used to effect complete separation and identification of the pure compounds in the combined fractions. The presence or absence of functional groups in an organic molecule determines the manner in which that organic molecule will fragment. The presence or absence of various mass peaks in each spectrum was used to deduce the structure of the compounds. The compounds identified are phthalic acid, butane, methyl palmitate, n-hexadecanoic acid, phytol etc. 


\section{Conclusion}

The present study has investigated the efficacy of Calotropis procera which can be considered in folklore or traditional medicine, edible vegetable and animal forage. The overall results showed that the crude fractions of this plant have an appreciable antibacterial activity on the selected microorganisms and also the chemical compounds present in the plant simplifies that $C$. procera extracts could maximally serve as alternative to highly rated synthesized drugs whose costs are unaffordable by the common man.

\section{References}

1. De Smet P (2005) Herbal Medicine in Europe: Relaxing regulatory standards. New England Journal of Medicine 352 (12): 1176-1178.

2. Griggs JK, Mmander HP, Towers GHN, Tailor RSI (2001) The effects of activity of medicinal plants from Nepa. J Ethnopharmacol 77(2): 247252.

3. Ahmed I, Mehmood Z, Mohammed F (1998) Screening of some Indian medicinal plants of their antimicrobial properties. Journal of Ethnopharmacology 62(2): 183-193.

\section{ISSN: 2574-1241}

DOI: 10.26717/BJSTR.2019.18.003124

Asoso Oluwakemi Sola. Biomed J Sci \& Tech Res

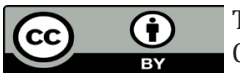

This work is licensed under Creative Commons Attribution 4.0 License

Submission Link: https://biomedres.us/submit-manuscript.php
4. Akharaiyi FC, Boboye B (2010) Antibacterial and phytochemical evaluation of three medicinal plants. Journal of Natural Products 3: 2734.

5. Stevens PF (2012) Angiosperm phylogeny Website.

6. Martins S, Amorim ELC, Peioxoto Sobrinho FJS, Saraiva AM, Pisciottano MNC, et al. (2013) Antibacterial activity of crude methanolic extracts and fractions obtained from Larrea tridentata leaves. Indeed Crops prod 41: 306-311.

7. Zhang LL (2014) Preparation and antimicrobial activity of tannin polymers from Platycarya strobilacea infructescence. Materials Research Innovations 18(2): 21049.

8. Nenaah G (2013) Antimicrobial activity of Calotropis procera Ait. (Asclepiadaceae) and isolation of four flavonoids glycosides as the active constituents. World Journal of Microbiology and Biotechnology 29(7): 1255-1262.

9. Ogundare, Adetuyi, Adeyosoye (2006) Antibacterial activities of Vemonia tenorreana. African Journal of Biotechnology 5(18): 1663-1668.

10. (2015) CLSI- Clinical and Laboratory Standards Institute. Methods for antimicrobial dilution and disk susceptibility testing of infrequently isolated or fastidious bacteria. Approved standard M45-A2 ( $3^{\text {rd }}$ edn.). Wayne, PA: Clinical and Laboratory Standards Institute p. 99

$\begin{array}{ll}\text { BIOMEDICAL } & \text { Assets of Publishing with us } \\ \text { RESEARCHES } & \text { - Global archiving of articles } \\ \text { - Immediate, unrestricted online access } & \text { - Rigorous Peer Review Process } \\ & \text { - Authors Retain Copyrights } \\ \end{array}$

